\title{
Systemically and topically supplemented leptin fails to reconstitute a normal angiogenic response during skin repair in diabetic ob/ob mice
}

\author{
B.Stallmeyer, J. Pfeilschifter, S. Frank \\ Centre of Pharmacology, University Hospital, Johann Wolfgang Goethe University, Frankfurt am Main, Germany
}

\begin{abstract}
Aims/hypothesis. In diabetic patients impaired wound healing conditions are a therapeutic problem of clinical importance. Recently, we showed that supplemented leptin induced an acceleration of impaired wound closure in diabetic $o b / o b$ mice by reversion of the delayed re-epithelialization process. Additionally, angiogenesis is central to a normal repair. As leptin has been reported to represent an angiogenic factor, we hypothesized that leptin-mediated angiogenic processes at the wound site might participate in leptin-mediated improvement of disturbed repair in $o b / o b$ mice. Methods. Using a model of excisional wounding, $\mathrm{C} 57 \mathrm{BL} / 6 \mathrm{~J}-o b / o b$ mice were treated systemically and topically with recombinant murine leptin during the phase of repair. Changes in blood glucose concentrations and body weight were monitored. We measured expression of the vascular endothelial growth factor (VEGF) and the endothelial cell marker protein CD31 as a read-out for angiogenic processes at the wound site.
\end{abstract}

Results. Expression of VEGF protein upon injury was reduced (30 to $40 \%$ ) in $o b / o b$ mice compared with wild-type C57BL/6 animals. Systemic and topical administration of leptin reconstituted normal wound VEGF expressions but failed to reverse the strongly reduced angiogenic response in $o b / o b$ mice. Immunohistochemistry confirmed that the epithelium and blood vessels located in the granulation tissue expressed the functional leptin receptor obRb isoform during skin repair.

Conclusion/interpretation. These data suggest that leptin reconstituted epithelial expression of VEGF during skin repair in $o b / o b$ mice but failed to improve wound angiogenesis in the granulation tissue. Thus, the accelerated wound closure observed in leptinsupplemented $o b / o b$ mice is not coupled to an improved wound angiogenesis. [Diabetologia (2001) 44: 471-479]

Keywords Wound healing, angiogenesis, VEGF, CD31.
Cutaneous wound healing involves a series of tissue movements such as haemorrhage, granulation tissue

Received: 27 September 2000 and in revised form: 31 October 2000

Corresponding author: S. Frank, PhD, pharmazentrum frankfurt, Institut für Allgemeine Pharmakologie und Toxikologie, Klinikum der JWG-Universität Frankfurt/Main, TheodorStern-Kai 7, D-60590 Frankfurt/Main, Germany

Abbreviations: CD, cluster of differentiation; $d b / d b$, diabetes/ diabetes; i.p., intraperitoneally; $o b / o b$, obese/obese; VEGF, vascular endothelial growth factor. formation, re-epithelialization and angiogenesis to reconstitute the injured skin region [1]. A number of pathological conditions are, however, known which severely interfere with a coordinated, and, thus, a successful wound closure. Three prototypic chronic wounds are of clinical importance: decubitus or pressure, venous, and the diabetic ulcers [2]. For the development of diabetic ulcers, the sensory neuronal impairment of the foot plays an important part because ulcerations develop over bony prominences which are exposed to excessive pressures. The pathogenic abnormalities of neurons in diabetes [3] are probably closely linked to vascular changes, as endo- 
neural microvessels show an impaired vascular flow [4] and endothelial proliferation with enhanced capillary closure [5]. As the chronic wound develops, however, a delay in angiogenic processes becomes obvious, as the presence of hypoxia at the wound site is well established for diabetic ulcers [6].

Angiogenic activities have been described for a series of mediators using in vitro assays. In particular, vascular endothelial growth factor (VEGF) potently mediates endothelial cell proliferation in vitro [7] and is expressed in large amounts by epidermal cells during cutaneous wound healing [8]. The expression of VEGF remains high during granulation tissue formation [8] when wound angiogenesis normally occurs. By contrast, VEGF expression has been shown to be strongly reduced during healing in diabetic diabetes/diabetes $(d b / d b)$ mice [9] whose disease resembles human Type II (non-insulin-dependent) diabetes mellitus [10] and who suffer from severely disturbed wound healing conditions [11]. In addition to $d b / d b$ mice, obese/obese $(o b / o b)$ mice represent a second diabetes-obesity syndrome animal model which has been extensively studied. Homozygous animals have a deficiency of functional leptin [12] which leads to hyperphagia, impaired reproduction, decreased thermogenesis and reduced growth. More importantly, $o b / o b$ animals are characterized by a diabetic phenotype which is due to insulin resistance and is associated with a secondary hyperinsulinaemia [10]. Moreover, $o b / o b$ mice suffer from impaired wound healing conditions. The most prominent site of action for leptin is the hypothalamus [13]. Because hyperinsulinaemia and insulin resistance can be produced by inducing hypothalamic lesions, the central nervous system (CNS) is believed to have a major role in insulin action or secretion. Accordingly, the effects of leptin replacement in $o b / o b$ animals are impressive. Within hours both glucose and insulin concentrations begin to decline [14]. The re-adjustment of the metabolic state of these animals is associated with an improved wound healing. Recently, we showed that epithelial proliferation at the wound margins was enhanced, resulting in an accelerated re-epithelialization process [15]. Moreover, leptin had a direct effect on wound keratinocytes because even topically applied leptin re-adjusted epithelial defects without affecting the disturbed metabolic state of the animals [15]. In parallel, the expression of the functional leptin receptor $\mathrm{obRb}$ has been shown in subcutaneous vessels of wounded skin [16]. Because angiogenic processes are central to repair, and because hypoxia is involved in the development of chronic wounds associated with a diabetic state [6], we investigated whether a leptin-driven angiogenic response at the wound site might participate in the improvement of wound closure. This hypothesis is supported by two recent reports which describe leptin as a potent angiogenic factor $[17,18]$.
In this study we show that systemically and topically applied leptin increased the reduced VEGF expression at wound sites in $o b / o b$ mice. Leptin treatment did not, however, markedly increase the angiogenic response that is normally observed in healthy animals who are injured.

\section{Subjects and methods}

Animals. Female C57BL/6J-ob/ob and C57BL/6 control mice were obtained from The Jackson Laboratory (Maine, USA) and maintained under a $12 \mathrm{~h}$ light $/ 12 \mathrm{~h}$ dark cycle at $22^{\circ} \mathrm{C}$ until they were 8 weeks of age. At this time they were caged individually, monitored for body weight and wounded as described below.

Leptintreatment of mice. To investigate the function of systemically applied leptin during the wound healing period, female $\mathrm{C} 57 \mathrm{BL} / 6 \mathrm{~J}-o b / o b$ mice were injected intraperitoneally (i.p.) once a day at 0800 hours with murine recombinant leptin $5 \mu \mathrm{g} / \mathrm{g}$ body weight in $0.5 \mathrm{ml}$ phosphate-buffered saline (PBS) per injection for 13 days. To investigate the effect of locally applied leptin on the wound healing process, wounds of female C57BL/6J-ob/ob mice were covered with $1 \mu \mathrm{g}$ leptin in $20 \mu \mathrm{l}$ PBS twice a day (0800 hours, 2000 hours). To this end, the leptin/PBS solution was applied directly onto the surface of the wound scabs. Due to their spongy structures, the scabs allowed the leptin-containing PBS-drop to draw in rapidly (within minutes). Thus, it is tempting to argue that the leptin/PBS-treated scabs now served as a reservoir of recombinant leptin. The diffusion processes from the scab most likely targeted the recombinant leptin directly towards the underlying tissues. Control mice were treated with PBS alone. Murine recombinant leptin was from R \& D systems (Wiesbaden, Germany).

Wounding and preparation of wound tissues. To examine leptin functions on the wound healing process, six full-thickness wounds were created on each rodent and skin biopsy specimens from four animals were obtained 1, 3, 5, 7 and 13 days after injury as described recently [19]. For leptin-treated or PBStreated $o b / o b$ mice, body weight and blood glucose concentrations (Accutrend sensor, Boehringer Mannheim, Germany) were measured. For every experimental time-point, the wounds from four animals and the non-wounded back skin from four animals, respectively, were combined and used for RNA ( $n=12$ wounds) and protein isolation ( $n=8$ wounds). All animal experiments were carried out according to the guidelines and with permission from the local government of Hessen.

$R N A$ isolation and RNase protection analysis. Isolation of RNA was done as described previously [20]. We used $20 \mu \mathrm{g}$ of total RNA from wounded or non-wounded skin for RNase protection assays. The RNase protection assays were carried out as described previously [19], with at least two different sets of RNA from independent wound-healing experiments. A $316 \mathrm{bp}$ fragment corresponding to the murine $\mathrm{VEGF}_{120}$ cDNA [19] and a 222 bp fragment corresponding to nucleotides 1620-1841 of the murine CD31 cDNA [21] were used as templates. The RNases A and T1 were from Roche Biochemicals (Mannheim, Germany).

Western blot analysis. Skin lysates were prepared as described previously [19]. Total protein $(50 \mu \mathrm{g})$ from non-wounded back 

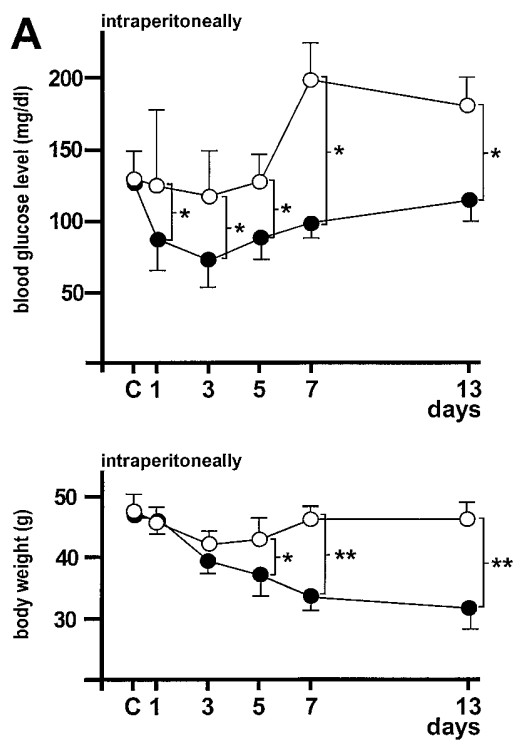

Fig.1 (A, B). Effect of intraperitoneally and topically supplemented leptin on blood glucose concentrations and body weight in $\mathrm{C} 57 \mathrm{BL} / 6 \mathrm{~J}-o b / o b$ mice. C57BL/6J-ob/ob mice were treated with leptin intraperitoneally (i.p.) or topically (top) as previously described. PBS $(\bigcirc)$ or leptin $(O)$ administration, respectively, is indicated in the figure. PBS-treated $o b / o b$ mice were used as controls. (A) and (B), blood glucose concentrations and body weight were measured for intraperitoneally injected (A), or topically treated (B) animals at the indicated experimental time-points. Three animals $(n=3)$ were analysed for every experimental time-point. Data are expressed as $\mathrm{mg}$ / $\mathrm{dl}$ (for blood glucose concentrations), or g (for body weight). Mean changes \pm SD in blood glucose molarity concentrations, or body weight, respectively, are shown. $* * p<0.01 ; * p<0.05$; NS (not significant) compared with the conditions as indicated in the brackets

skin and 1, 3, 5, 7 and 13 day wounds of C57BL/6 control mice or $o b / o b$ mice treated with either PBS, or leptin was separated using SDS-gel-electrophoresis. After being transferred to a PVDF membrane, CD31-specific proteins were detected using a polyclonal antiserum directed against murine CD31 (Santa Cruz, Heidelberg, Germany). A secondary antibody coupled to horseradish peroxidase (Biomol, Hamburg, Germany) and the ECL detection system (Amersham, Braunschweig, Germany) were used to visualize CD31 protein.

Histological analysis. The C57BL/6 mice were wounded as described above. At day 13 after wounding mice were killed and complete wounds were isolated from the middle of the back, bisected and frozen in tissue freezing medium. Immunohistochemistry was carried out on six micrometer frozen sections as described previously [19]. Sections were subsequently incubated for $60 \mathrm{~min}$ at room temperature with a polyclonal antibody generated against the C-terminus of the murine obRb leptin receptor subtype (Santa Cruz) diluted (1:100) in PBS, $0.1 \%$ bovine serum albumin.

Enzyme-linked immunosorbent assay. Total protein $(50 \mu \mathrm{g} \mathrm{di-}$ luted in lysis buffer to a final volume of $50 \mu \mathrm{l}$ ), from nonwounded skin lysates, and wound lysates were subsequently analyzed for the presence of immunoreactive $\mathrm{VEGF}_{164}$ protein
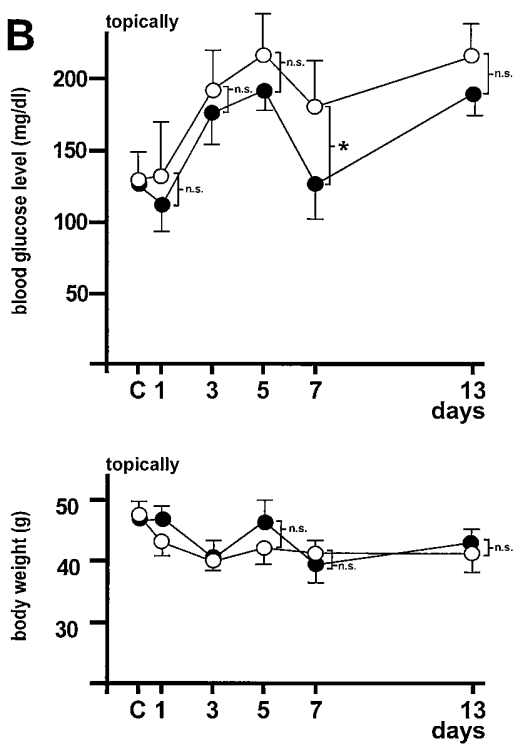

by enzyme-linked immunosorbent assay (ELISA) using the Quantikine murine VEGF $_{164}$ kit (R \& D systems) as described by the manufacturer.

Statistical analysis. Data are shown as means \pm SD. Data were analysed by unpaired Student's $t$ test on raw data using Sigma Plot (Jandel Scientific, Erkrath, Germany). A $p$ value of less than 0.05 was considered to be significant.

\section{Results}

Systemically, but not topically supplemented leptin, reversed the diabetic phenotype in ob/ob mice. Leptindeficient $o b / o b$ mice are characterized by hyperphagia, impaired reproduction, decreased thermogenesis, reduced growth and, finally, by a diabetic phenotype which is due to insulin resistance and hyperinsulinaemia [10]. Replacement of leptin leads to re-adjustment of the diabetic state by rapidly decreasing glucose and insulin concentrations [14]. Leptin-mediated re-adjustment of the metabolic state might underlie the improved healing in $o b / o b$ mice rather than a direct effect of leptin at the wound site. We assessed the consequences of systemic and topical supplementation of leptin for blood glucose concentrations and body weight during repair. Recombinant murine leptin proved to be physiologically active because intraperitoneal (i.p.) injection of recombinant leptin $(5 \mu \mathrm{g} / \mathrm{g}$ body weight, once a day) significantly decreased blood glucose concentrations and also body weight (Fig. 1). Importantly, topically applied leptin $(1 \mu \mathrm{g}$ in $20 \mu \mathrm{l}$ PBS for each wound twice a day) only marginally reduced blood glucose concentrations and no changes in body weight were observed in mice treated topically with leptin (Fig.1). These data strongly suggest that topically applied leptin given in the smallest amounts $(1 \mu \mathrm{g}$ in $20 \mu \mathrm{l}$ PBS for each wound twice a day) did not re-adjust the diabetic phenotype of the animals. Thus, the topical ap- 

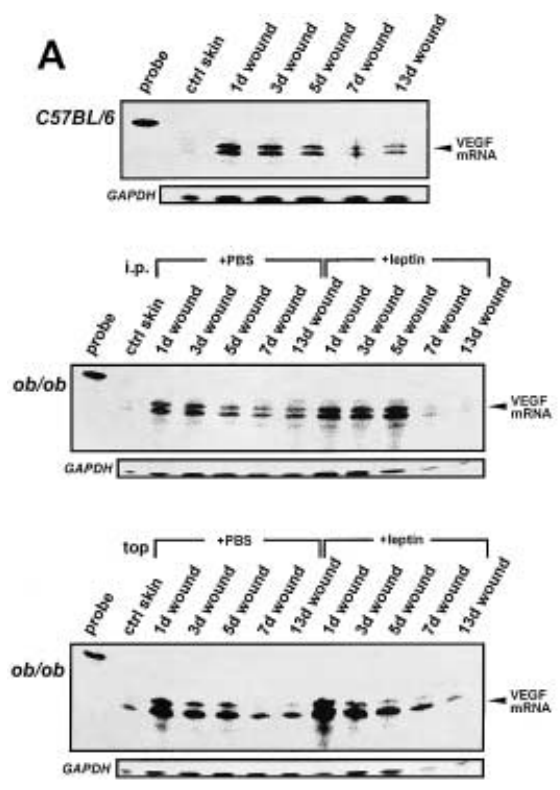

Fig.2 (A, B). Regulation of VEGF mRNA expression during wound healing in $\mathrm{C} 57 \mathrm{BL} / 6$ control and $\mathrm{C} 57 \mathrm{BL} / 6 \mathrm{~J}-\mathrm{ob} / \mathrm{ob}$ diabetic mice. Mice were treated systemically and topically as previously described. (A) total cellular RNA $(20 \mu \mathrm{g})$ from nonwounded and wounded back skin of C57BL/6, or C57BL/6J$o b / o b$ mice treated intraperitoneally (i.p.) or topically (top) with PBS or leptin as indicated was analysed by RNase protection assay for the presence of VEGF mRNA. For every experimental time-point, three wounds, each from four animals (total of $n=12$ wounds) were pooled for analysis. C57BL/6 (O) or PBS (ㅇ) and leptin (O) treated $o b / o b$ mice, respectively, are indicated in the figure. The time after injury is indicated on top of each lane. Control skin refers to non-wounded skin. 1000 counts/min of the hybridization probe were added to the lane labeled probe. Expression of GAPDH mRNA is shown as a loading control in the bottom panels. The degree of VEGF mRNA induction as assessed by PhosphoImager (Fuji) analysis of the radiolabelled gels is shown schematically in $(\mathbf{B}) \cdot \mathrm{d}=$ day

plication of leptin allows us to exclusively investigate direct leptin functions at the wound site.

Wound size was significantly reduced after leptin treatment. Wound size was assessed at day 13 post-wounding in PBS-treated (control) and systemically treated (i. p., $5 \mu \mathrm{g} / \mathrm{g}$ body weight, once a day) $o b / o b$ mice by measuring wound diameters. We determined an average wound size of $5.5 \pm 0.8 \mathrm{~mm}$ compared with $2.8 \pm$ $0.7 \mathrm{~mm}$ for PBS-treated control compared with leptin-treated $o b / o b$ mice $(n=24$ wounds, $p<0.01)$. Recently, a complete wound size kinetics (day 1 to 8 postwounding) that shows the potency of systemically and also topically applied leptin to serve as a wound healing factor in $o b / o b$ mice has been studied in detail [16].

Expression of VEGF $m R N A$ and protein during repair in ob/ob mice. Epidermal keratinocytes repre-

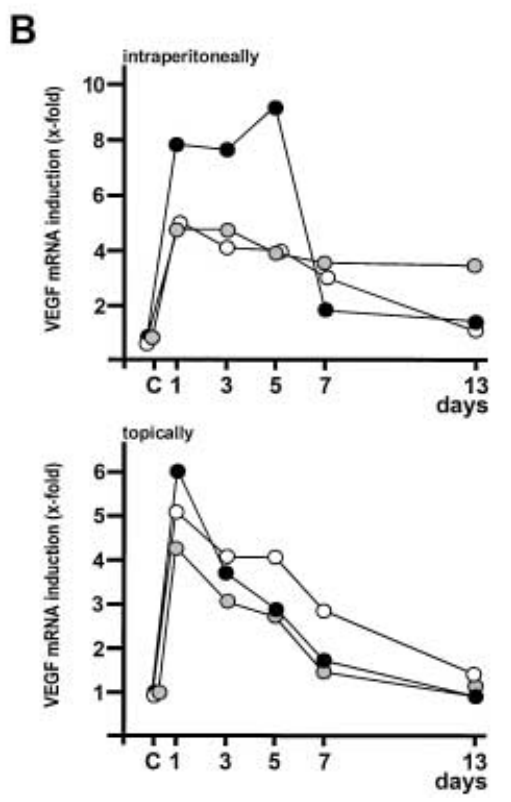

sent the principal source of VEGF during cutaneous repair and VEGF expression remains low in the underlying dermis [8]. Thus, the avascular epithelium regulates angiogenesis in the newly forming stroma through a paracrine mechanism involving VEGF [22]. To investigate the regulation of VEGF mRNA and protein expression during wound healing, we carried out RNase protection assays (Fig. 2) and ELISA analysis (Fig. 3). Two different protected fragments were obtained with RNA from normal and wounded skin, corresponding to different forms of VEGF mRNA (Fig.2A). The longer protected fragment is generated by RNA encoding the murine VEGF $_{120}$, whereas the shorter protected fragment is generated by mRNAs encoding the murine $\mathrm{VEGF}_{164}$ and $\operatorname{VEGF}_{188}[9,19]$. Although the closure of excisional wounds in $o b / o b$ mice was delayed, we did not observe differences in VEGF mRNA expressions at the wound site in vehicle (PBS, i.p.)-treated $o b / o b$ mice when compared with healthy C57BL/6 control mice (Fig. 2A). By contrast, i.p. injection of leptin during repair considerably increased VEGF mRNA expression in $o b / o b$ mice (Fig. 2A and B) compared with control (C57BL/6) or vehicle (PBS) -injected animals. Topical application of leptin, which did not significantly alter the metabolic state of the animals (Fig.1), only slightly increased local VEGF mRNA expressions within the wound tissue (Fig. 2A and B). It is important to note for the RNase protection assay experiments that total RNA isolated from 12 wounds $(n=12$ wounds) from four different animals was analysed for each experimental time-point.

The effects observed at the mRNA concentrations were in part reflected in wound VEGF protein expression. As shown in Figure 3 and partially contrasting with the data obtained at the mRNA level, PBSinjected $o b / o b$ mice expressed considerably reduced 


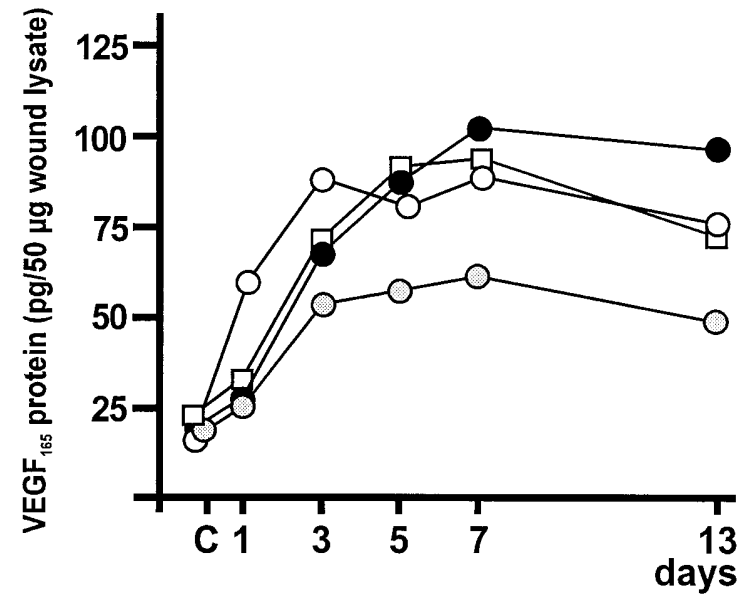

Fig.3. Leptin reconstitutes reduced VEGF protein expressions during repair in $\mathrm{C} 57 \mathrm{BL} / 6 \mathrm{~J}-o b / o b$ mice. Total protein $(50 \mu \mathrm{g})$ from lysates of non-wounded and wounded back skin (day 1, 3, 5, 7, and 13 after injury) of C57BL/6 control mice (O), or C57BL/6J-ob/ob mice treated intraperitoneally (오) (i. p.) or topically ( ) (top) with PBS or leptin ( $\square$ ) as indicated were analysed by ELISA for the presence of $\mathrm{VEGF}_{164}$-specific proteins. Two wounds of the backs of four animals $(n=8)$ were excised for each experimental time-point and used for protein isolation. Control skin refers to non-wounded back skin. Animals and PBS or leptin treatment, respectively, are indicated in the figure

amounts of VEGF protein upon injury compared with C57BL/6 control mice. Most notably at day 5 and 7 post-wounding, systemically and topically applied leptin reconstituted reduced VEGF protein expressions in $o b / o b$ mice to expressions similar to those measured in wounds isolated from C57BL/6 control animals. These time-points of repair represent the peak of angiogenic movements in the granulation tissue. At the late phase of repair (day 13 post-wounding) and in contrast to topical application, only systemically applied leptin led to increased VEGF protein expressions compared with C57BL/6 control mice. Note that every experimental timepoint represents eight wounds $(n=8)$ isolated from four different animals.

The great decrease in formation of vascular endothelium in wounds of ob/ob mice could not be reversed by the treatment with leptin. As a next step, we investigated a possible functional consequence of reduced VEGF expressions in $o b / o b$ mice, of re-adjusted VEGF expressions in leptin-treated animals for vascular remodelling and, subsequently, the angiogenic response. To this end, we measured expression of CD31 which represents a constitutively expressed, highly specific marker for vascular and lymphatic endothelial cells. A strong angiogenic response was induced after injury in C57BL/6 control animals (Fig. 4). The loss of tissue associated with excisional wounding was reflected in an overall loss of CD31 protein that served as a read-out for the presence of endothelial cells at the wound site (Fig.5). Notably, the observed increase in CD31 mRNA expressions after injury (Fig. 4A and B) clearly translated in re-increasing CD31 protein expressions as repair proceeds (Fig. 5). For PBS-treated $o b / o b$ mice, we assessed a markedly decreased expression of CD31 mRNA after wounding (Fig. 4) which was paralleled by a large reduction in CD31 protein synthesis (Fig.5). Even the systemical application of leptin, although it reconstituted VEGF protein expression in the wounds (Fig. 3) only, however, moderately improved the angiogenic response in $o b / o b$ mice, as CD31 expression appeared to be only weakly stimulated by leptin (Fig. 5). Consistently, topical application of leptin totally failed to induce CD31 mRNA (Fig. 4) and also protein (data not shown) reflecting the situation in PBS-treated $o b / o b$ mice.

Epidermal keratinocytes represent the major target cells for leptin actions during repair. Because we observed the failure of systemically and especially topically applied leptin to improve wound angiogenesis in $o b / o b$ mice, we looked for the expression of the functional leptin receptor obRb in the newly formed vascular endothelium at the wound site. This was important, as endothelial cells have been reported to express the obRb receptor variant $[17,18]$. An absence of obRb-specific signals might provide an explanation for the failure of leptin treatment to trigger angiogenesis during repair in $o b / o b$ mice. We carried out immunohistochemistry for the functional leptin receptor variant obRb on frozen sections of 13-day wounds isolated from C57BL/6 control mice. Small vessels located in the granulation tissue beneath the freshly formed neo-epithelium did indeed express the obRb receptor subtype, and thus, should be sensitive for leptin-mediated actions (Fig. 6). More importantly, we have reported a direct effect of leptin on keratinocyte proliferation and wound re-epithelialization [15], therefore finally confirming that the epidermal keratinocytes represent the major target cells for leptin action during repair, because the obRb receptor subtype could be detected extensively in the epithelium and not in blood vessels located in the granulation tissue (Fig. 6).

\section{Discussion}

The present model of body-weight regulation suggests that the central nervous system (CNS) plays a key part in determining food intake and energy expenditure as a response to afferent signals which are generated in proportion to the size of the adipose tissue stores [23]. Three adipose tissue-related signal molecules participate in the regulation of body weight: insulin, leptin and adrenal steroids [24]. 

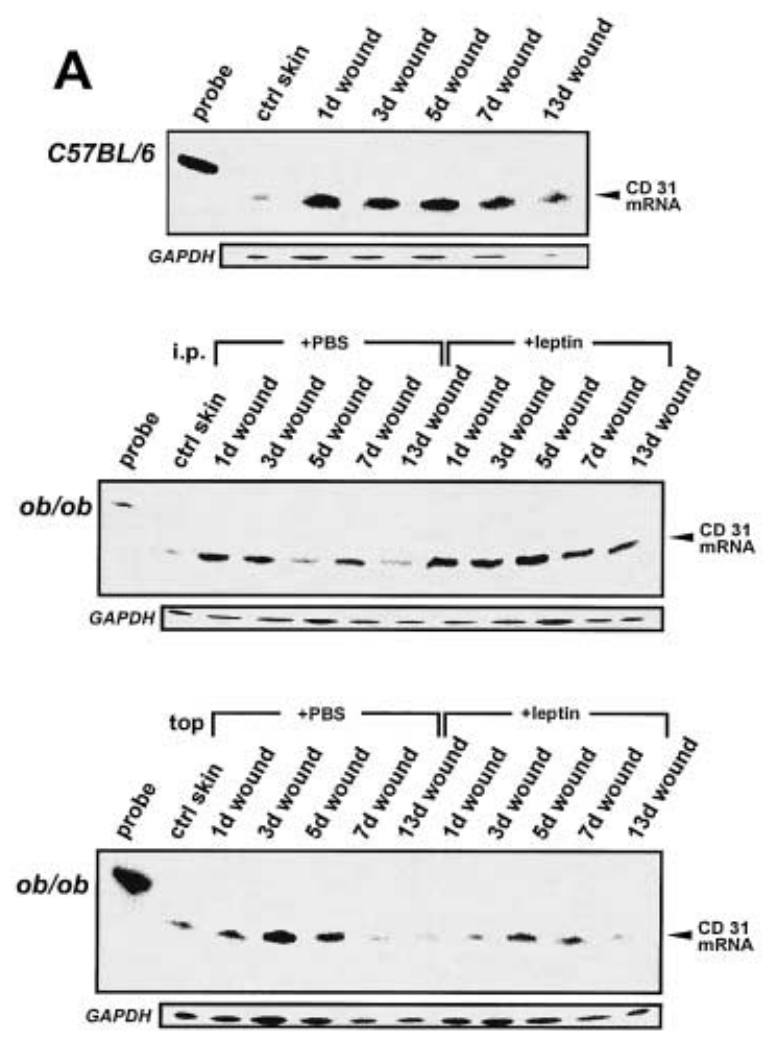

Fig.4(A, B). Regulation of CD31 mRNA expressions during healing in C57BL/6 control and diabetic C57BL/6J-ob/ob mice. Mice were treated systemically and topically as previously described. (A) total cellular RNA $(20 \mu \mathrm{g})$ from non-wounded and wounded back skin of C57BL/6, or C57BL/6J-ob/ob mice treated intraperitoneally (i.p.) or topically (top) with PBS or leptin as indicated was analysed by RNase protection assay for the presence of CD31 mRNA. C57BL/6 (O) or PBS (여) and leptin (O) treated $o b / o b$ mice, respectively, are indicated in the figure. For every experimental time-point, three wounds each from four animals (total of $n=12$ wounds) were pooled for analysis. The time after injury is indicated on top of each lane. Control skin refers to non-wounded skin. 1000 counts/min of the hybridization probe were added to the lane labelled probe. Expression of GAPDH mRNA is shown as a loading control in the bottom panels. The degree of CD31 mRNA induction as assessed by PhosphoImager (Fuji) analysis of the radiolabeled gels is shown schematically in $(\mathbf{B})$. $\mathrm{d}=\mathrm{day}$

Apart from its actions in the peripheral body, insulin controls food intake by binding its receptors in the medial basal hypothalamus [25] and mediates a dose-dependent reduction in food ingestion [26-28]. A second player within this regulatory scenario is leptin, which is produced by adipocytes [29] and circulates at expressions that are directly proportional to body adiposity in animals $[30,31]$ and humans $[30$, 32-35]. Similarly to insulin, leptin exerts important regulatory functions in the hypothalamic region, the functional obRb receptor subtype being the predomi-
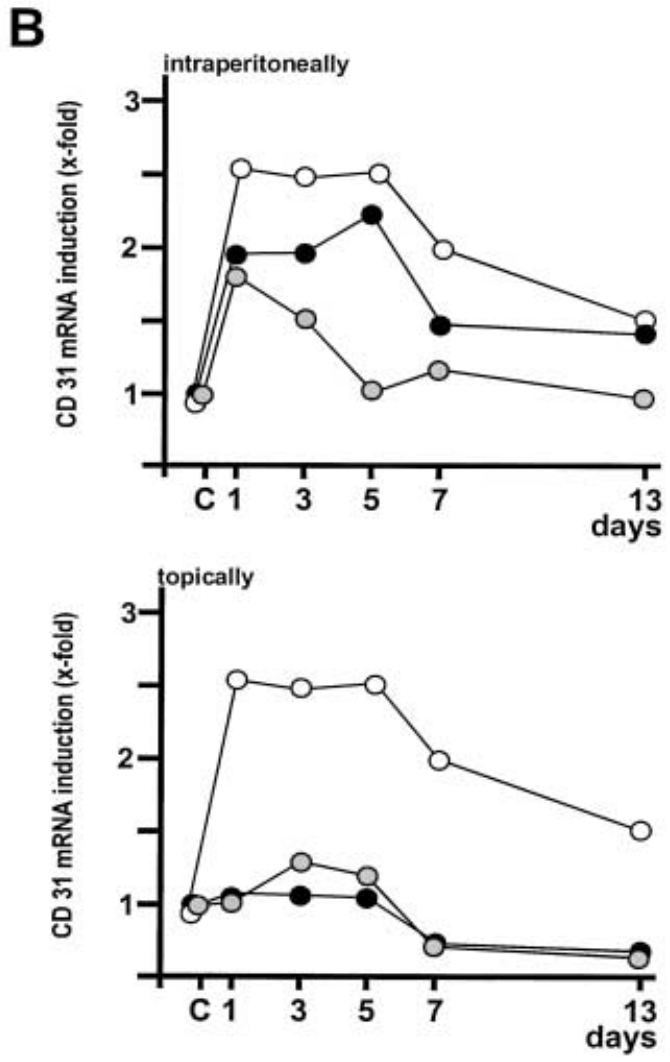

nantly expressed isoform in hypothalamic neurons [36-38]. Both the insulin and leptin system are believed to be connected. Evidence emerged from work on rodents suffering from diabetes-obesity syndromes. These animals ( $o b / o b$ and $d b / d b$ mice) have been shown to be defective in leptin signalling, as leptin (for $o b / o b$ mice) or its functional receptor (for $d b /$ $d b$ mice and $f a / f a$ Zucker rats), respectively, were absent due to mutations in the corresponding genes [12, 39]. These leptin-deficient $(o b / o b)$ or resistant $(d b /$ $d b$ ) rodents are characterized by high insulin concentrations [40] which finally lead to activation of anabolic signalling pathways in the hypothalamus. Because insulin injected into the CNS failed to mediate a reduction of food intake in leptin-resistant $f a / f a$ Zucker rats, it has been proposed that insulin action in the hypothalamus is ineffective in the absence of leptin signalling and thus requires a functional leptin system to function normally. As a consequence of the disturbed interaction between insulin and leptin in the CNS, the activation of anabolic pathways and hyperphagia occurs. The high circulating insulin concentrations finally lead to fat storage and the outcome is extreme obesity in these animals.

Recently, extrahypothalamic actions have also been described for leptin. Thus, leptin might be a cytokine that carries multifunctional properties. As the obRb leptin receptor isoform is expressed in various peripheral tissues [41, 42], it might also exert additional biological functions. Accordingly, leptin has 

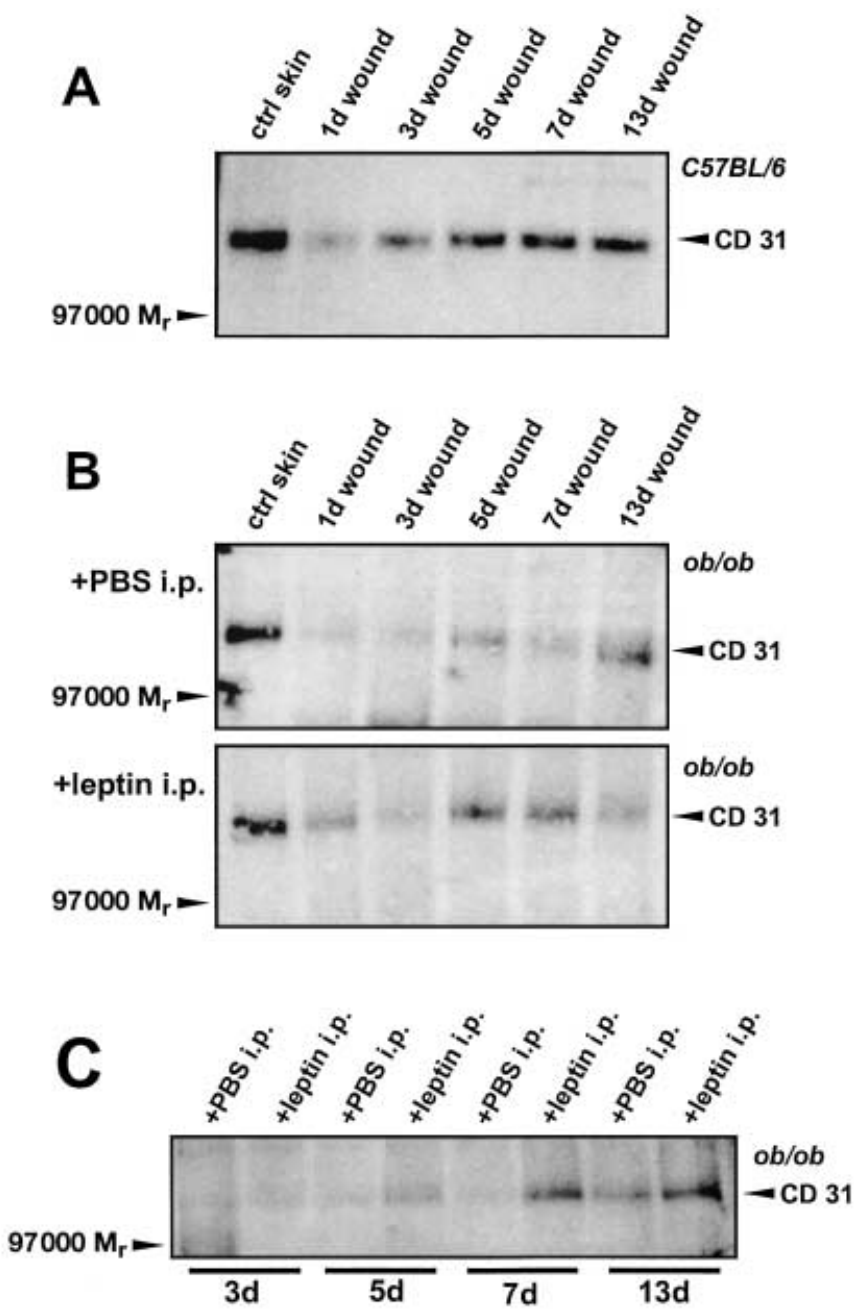

Fig.5(A-C). Leptin fails to reconstitute a prominent angiogenic response in C57BL/6J-ob/ob mice. Total protein $(50 \mu \mathrm{g})$ from lysates of non-wounded and wounded back skin (day 1 , 3, 5, 7 and 13 after injury, indicated for each lane) of C57BL/6 control mice (A) and C57BL/6J-ob/ob mice (B and C) systemically treated with PBS or leptin as indicated were analysed by immunoblotting for the presence of CD31-specific proteins. Two wounds of the backs of four animals $(n=8)$ were excised for each experimental time-point and used for protein isolation. Control skin refers to non-wounded back skin. $\mathrm{d}=$ day

been shown to trigger reproductive functions in vivo $[43,44]$ and to serve as a mitogen for a growing number of cell types such as endothelial cells, monocytes, lung epithelial cells and pancreatic beta cells in vitro $[16,45-48]$. In agreement with these findings, we could show an additional in vivo function of leptin independently of the regulation of body metabolism: leptin serves as a potent mitogen for skin epidermal keratinocytes during the process of cutaneous wound repair. Moreover, the capability of leptin to trigger keratinocyte proliferation in vitro was similar to the most active keratinocyte mitogens epidermal growth factor (EGF) or keratinocyte growth factor (KGF) [15]. The study has been carried out in leptin-deficient $o b / o b$ mice which suffer from severe wound healing disorders. This phenomenon is well known and the wound healing disturbances that have been observed were referred to the diabetic phenotype of the animals. The systemic application of leptin as well as the topical application of minute amounts of leptin $(1 \mu \mathrm{g}$, twice a day) directly to the wounds strongly enhanced wound closure in this model of excisional repair. More importantly, a systemic, but not topical application of leptin finally re-adjusted the diabetic phenotype in the animals, so that we could prove a direct effect of leptin on keratinoyctes of the wound margins [15]. The beneficial effects of leptin on wound healing processes in $o b / o b$ mice have consistently been reported [16], although this study did not investigate the mechanisms of leptin actions during repair. This work [16], however, showed the expression of the obRb leptin receptor variant in subcutaneous vessels of the wound bed which might suggest a potential function of leptin on the vascular endothelium. This hypothesis is strongly supported by two recent reports that identified leptin as an angiogenic factor $[17,18]$. Human umbilical venous endothelial cells (HUVEC) express the obRb receptor and respond to a leptin stimulus with proliferation. Moreover, leptin triggered phosphorylation of mitogen-activated protein kinases ERK1/2 and angiogenesis in a chick chorioallantoic membrane assay [17]. In line with these findings, obRb has been shown to be expressed in the human vasculature and leptin triggered neovascularization in the corneas from normal but not from leptin-resistant fa/fa Zucker rats [18]. For these reasons, we hypothesized that a leptin-mediated angiogenic response, apart from its prominent mitogenic function on the epithelium, might participate in the accelerated wound closure processes in leptin-supplemented $o b / o b$ mice. Nevertheless, the measurement of wound haemoglobin and wound vessel density in $o b / o b$ mice treated with leptin did not suggest that leptin influenced the angiogenic processes during repair [16]. We decided to assess additional variables to measure leptin effects on wound angiogenesis: VEGF, representing a highly potent mitogen for endothelial cells [7] and CD31, a highly specific marker protein of vascular and lymphatic endothelial cells. As CD31 is constitutively expressed in these cells, the CD31 levels measured during repair served as a biochemical read-out of the angiogenic response at the wound site. Of note systemic and topical application of leptin in $o b / o b$ mice re-adjusted wound VEGF expressions, which were only moderately reduced in non-treated $o b / o b$ animals, to those measured in control mice. This observation combines the well-known phenomenon that the avascular epidermis regulates plasma protein extravasation and angiogenesis in the underlying dermis through a paracrine mechanism that crucially involves keratinocyte-derived VEGF secretion [22] and our report that leptin mediated a re-adjustment 


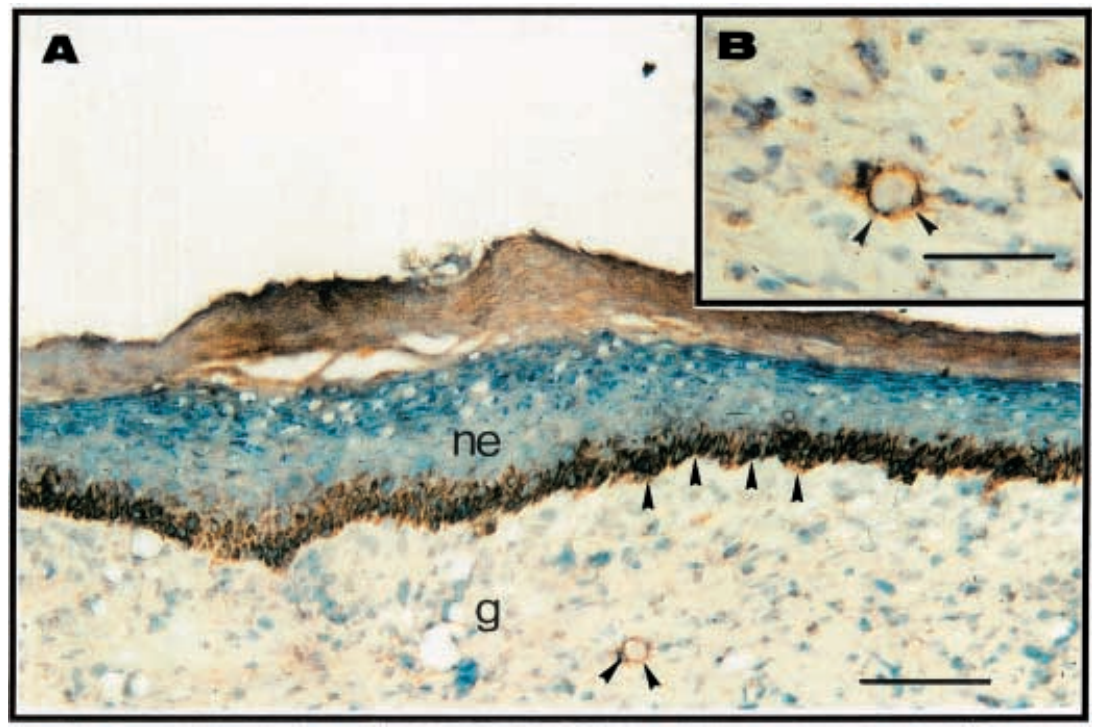

Fig. 6(A, B). Expression of the functional leptin receptor variant obRb during late repair (day 13 after injury). (A) frozen section from a 13-day wound isolated from a C57BL/6 control animal. The section was incubated with a monospecific polyclonal antibody against the obRb receptor subtype. (B) blood vessel shown in higher magnification. Sections were stained with the avidin-biotin-peroxidase complex system using 3-amino-9-ethylcarbazole as a chromogenic substrate. Nuclei were counterstained with hematoxylin. Strongly immunopositive signals within the sections are indicated with arrows. Scale bars are $100 \mu \mathrm{m}$ for $A$ and $50 \mu \mathrm{m}$ for (B). ne, neo-epithelium; $g$, granulation tissue

of impaired re-epithelialization processes in $o b / o b$ mice [15]. Thus, these data as well as immunohistochemistry, showing the epithelium as the predominant compartment expressing the obRb leptin receptor, suggest that leptin reconstitutes those parts of the angiogenic response that are mediated by wound keratinocytes, such as VEGF production. It is noteworthy that a correction of VEGF expressions at the wound site in $o b / o b$ mice did not result in an overall improvement of the angiogenic response. This might be due to diabetic-induced alterations of VEGF receptor expression in cutaneous vessels, but as no data from skin are currently available, this hypothesis remains speculative. A recent study showed a rapid degradation of $\mathrm{VEGF}_{164}$ protein by proteolytic activities of chronic wound lysates [49], and such a scenario might also occur and explain repair in $o b / o b$ mice.

Although the functional receptor obRb is expressed in cutaneous vessels [18] (this study), the replacement of leptin in $o b / o b$ mice resulted only in a marginal improvement of wound angiogenesis (as determined by CD31 expression) which was found to be nearly completely absent in these animals. Thus, the angiogenic capabilities of leptin observed in in vivo systems such as the chick chorioallantoic membrane assay [16], and, additionally, the rat cornea [18] could not be easily transferred to the skin organ system. Although epithelial-derived movements, such as proliferation [15] or VEGF expression (this study), were improved by leptin, the obRb expressing vascular endothelium located in the newly forming stroma is obviously not in a position to respond to leptin. Taken together, these data suggest that leptin potently drives epithelial processes during skin repair and that the accelerated wound closure observed in leptin-supplemented $o b / o b$ mice is not coupled to an improved wound angiogenesis.

Acknowledgements. This work was supported by a grant of the German Research Foundation (SFB 553) and by the Paul and Ursula Klein Foundation. We thank N. Kolb for excellent technical assistance. We gratefully acknowledge Dr M. Kock for his help with the animal experiments.

\section{References}

1. Martin P (1997) Wound healing - aiming for perfect skin regeneration. Science 276: 75-81

2. Falanga V (1993) Chronic wounds: pathophysiology and experimental considerations. J Invest Dermatol 100: 721-725

3. Bays HE, Pfeifer MA (1988) Peripheral diabetic neuropathy. Med Clin North Am 72: 1439-1464

4. Ram Z, Sadeh M, Walden R, Adar R (1991) Vascular insufficiency quantitatively aggravates diabetic neuropathy. Arch Neurol 48: 1239-1242

5. Tuck RR, Schmelzer JD, Low PA (1984) Endoneurial blood flow and oxygen tension in the sciatic nerves of rats with experimental diabetic neuropathy. Brain 107: 935-950

6. Pecaro RE (1991) The nonhealing diabetic ulcer - a major cause for limb loss. Prog Clin Biol Res 365: 27-43

7. Keck PJ, Hauser SD, Krivi G et al. (1989) Vascular permeability factor, an endothelial cell mitogen related to PDGF. Science 246: 1309-1313

8. Brown LF, Yeo KT, Berse B et al. (1992) Expression of vascular permeability factor (vascular endothelial growth factor) by epidermal keratinocytes during wound healing. J Exp Med 176: $1375-1379$ 
9. Frank S, Hübner G, Breier G, Longaker MT, Greenhalgh DG, Werner S (1995) Regulation of vascular endothelial growth factor expression in cultured keratinocytes. Implications for normal and impaired wound healing. J Biol Chem 270: 12607-12613

10. Coleman DL (1982) Diabetes-obesity syndromes in mice. Diabetes $31: 1-6$

11. Wetzler C, Kämpfer H, Stallmeyer B, Pfeilschifter J, Frank S (2000) Large and sustained induction of chemokines during impaired wound healing in the genetically diabetic mouse: prolonged persistence of neutrophils and macrophages during the late phase of repair. J Invest Dermatol 115: 245-253

12. Zhang Y, Proenca R, Maffei M, Barone M, Leopold L, Friedman JM (1994) Positional cloning of the mouse obese gene and its human homologue. Nature 372: 425-432

13. Elmquist JK, Maratos-Flier E, Saper CB, Flier JS (1998) Unraveling the central nervous system pathways underlying responses to leptin. Nat Neurosci 1: 445-450

14. Halaas JL, Gajiwala KS, Maffei M et al. (1995) Weight-reducing effects of the plasma protein encoded by the obese gene. Science 269: 543-546

15. Frank S, Stallmeyer B, Kampfer H, Kolb N, Pfeilschifter J (2000) Leptin enhances wound re-epithelialization and constitutes a direct function of leptin in skin repair. J Clin Invest 106: 501-509

16. Ring BD, Scully S, Davis CR et al. (2000) Systemically and topically administered leptin both accelerate wound healing in diabetic $o b / o b$ mice. Endocrinology 141: 446-449

17. Bouloumié A, Drexler HCA, Lafontan M, Busse R (1998) Leptin, the product of the ob gene, promotes angiogenesis. Circ Res 83: 1059-1066

18. Sierra-Honigmann MR, Nath AK, Murakami C et al. (1998) Biological action of leptin as an angiogenic factor. Science 281: 1683-1686

19. Frank S, Stallmeyer B, Kämpfer H, Kolb N, Pfeilschifter J (1999) Nitric oxide triggers enhanced induction of vascular endothelial growth factor expression in cultured keratinocytes $(\mathrm{HaCaT})$ and during cutaneous wound repair. FASEB J 13: 2002-2014

20. Chomczynski P, Sacchi N (1987) Single-step method of RNA isolation by acid guanidinium thiocyanate-phenol-chloroform extraction. Anal Biochem 162: 156-159

21. Xie YM, Muller WA (1992) Molecular cloning and adhesion properties of murine platelet/endothelial cell adhesion molecule 1. Proc Natl Acad Sci USA 90: 5569-5573

22. Detmar M, Yeo KT, Nagy JA et al. (1995) Keratinocyte-derived vascular permeability factor (vascular endothelial growth factor) is a potent mitogen for dermal microvascular endothelial cells. J Invest Dermatol 105: 44-50

23. Kaiyala KJ, Woods SC, Schwartz MW (1995) New model for the regulation of energy balance and adiposity by the central nervous system. Am J Clin Nutr 62: 1123S-1134S

24. Porte D Jr, Seeley RJ, Woods SC, Baskin DG, Figlewicz DP, Schwartz MW (1998) Obesity, diabetes and the central nervous system. Diabetologia 41: 863-881

25. van Houten M, Posner BI, Kopriwa BM, Brawer JR (1980) Insulin binding sites localized to nerve terminals in rat median eminence and arcuate nucleus. Science 207: 1081-1083

26. Ikeda H, West DB, Pustek JJ et al. (1986) Intraventricular insulin reduces food intake and body weight of lean but not obese Zucker rats. Appetite 7: 381-386

27. Foster LA, Ames NK, Emery RS (1991) Food intake and serum insulin responses to intraventricular infusions of insulin and IGF-I. Physiol Behav 50: 745-749

28. Woods SC, Lotter EC, McKay LD, Porte D Jr (1979) Chronic intracerebroventricular infusion of insulin reduces food intake and body weight of baboons. Nature 282: 503-505

29. Masuzaki H, Ogawa Y, Isse N et al. (1995) Human obese gene expression. Adipocyte-specific expression and regional differences in the adipose tissue. Diabetes 44: 855-858
30. Maffei M, Halaas J, Ravussin E et al. (1995) Leptin expressions in human and rodent: measurement of plasma leptin and ob RNA in obese and weight-reduced subjects. Nat Med 1: 1155-1161

31. Frederich RC, Hamann A, Anderson S, Lollmann B, Lowell BB, Flier JS (1995) Leptin expressions reflect body lipid content in mice: evidence for diet-induced resistance to leptin action. Nat Med 1: 1311-1314

32. Considine RV, Sinha MK, Heiman ML et al. (1996) Serum immunoreactive-leptin expressions in normal-weight and obese humans. N Engl J Med 334: 292-295

33. Considine RV, Considine EL, Willimas CJ et al. (1995) Evidence against either premature stop codon or the absence of obese gene mRNA in human obesity. J Clin Invest 96: 2720-2728

34. Lonnqvist F, Arner P, Nordfors L, Schalling M (1995) Overexpression of the obese (ob) gene in adipose tissue of human obese subjects. Nat Med 1: 950-953

35. McGregor GP, Desaga JF, Ehlenz K et al. (1996) Radiommunological measurement of leptin in plasma of obese and diabetic human subjects. Endocrinology 137: 1501-1504

36. Baskin DG, Kochan JP, Campfield LA et al. (1997) Localization of the leptin receptor long form protein and mRNA in the rat hypothalamus. Endo Soc Abstr: 95

37. Baskin DG, Seeley RJ, Kuijper JL et al. (1998) Increased expression of mRNA for the long form of the leptin receptor in the hypothalamus is associated with leptin hypersensitivity and fasting. Diabetes 47: 538-543

38. Mercer JG, Hoggard N, Williams LM, Lawrence CB, Hannah LT, Trayhurn P (1996) Localization of leptin receptor mRNA and the long form splice variant $(\mathrm{Ob}-\mathrm{Rb})$ in mouse hypothalamus and adjacent brain regions by in situ hybridization. FEBS Lett 387: 113-116

39. Chua SC Jr, Chung WK, Wu-Peng XS et al. (1996) Phenotypes of mouse diabetes and rat fatty due to mutations in the $\mathrm{OB}$ (leptin) receptor. Science 271: 994-996

40. Coleman DL (1978) Obese and diabetes. two mutant genes causing diabetes-obesity syndromes in mice. Diabetologia 14: $141-148$

41. Lollmann B, Gruninger S, Stricker-Krongrad A, Chiesi M (1997) Detection and quantification of the leptin receptor splice variants $\mathrm{Ob}-\mathrm{Ra}, \mathrm{b}$, and, e in different mouse tissues. Biochem Biophys Res Commun 238: 648-652

42. Hoggard N, Mercer JG, Rayner DV, Moar K, Trayhurn P, Williams LM (1997) Localization of leptin receptor mRNA splice variants in murine peripheral tissues by RT-PCR and in situ hybridization. Biochem Biophys Res Commun 232: 383-387

43. Chehab FF, Lim ME, Lu R (1996) Correction of the sterility defect in homozygous obese female mice by treatment with the human recombinant leptin. Nat Genet 12: 318-320

44. Chehab FF, Mounzih K, Lu R, Lim ME (1997) Early onset of reproductive function in normal female mice treated with leptin. Science 275: 88-90

45. Santos-Alvarez J, Goberna R, Sanchez-Margalet V (1999) Human leptin stimulates proliferation and activation of human circulating monocytes. Cell Immunol 194: 6-11

46. Tsuchiya T, Shimizu H, Horie T, Mori M (1999) Expression of leptin receptor in lung: leptin as a growth factor. Eur J Pharmacol 365: 273-279

47. Tanabe K, Okuya S, Tanizawa Y, Matsutani A, Oka Y (1997) Leptin induces proliferation of pancreatic beta cell line MIN6 through activation of mitogen-activated protein kinase. Biochem Biophys Res Commun 241: 765-768

48. Islam MS, Morton NM, Hansson A, Emilsson V (1997) Rat insulinoma-derived pancreatic beta-cells express a functional leptin receptor that mediates a proliferative response. Biochem Biophys Res Commun 238: 851-855

49. Lauer G, Sollberg S, Cole M et al. (2000) Expression and proteolysis of vascular endothelial growth factor is increased in chronic wounds. J Invest Dermatol 115: 12-18 